Academic Platform Journal of Engineering and Science

\title{
Kendiliğinden Yerleşen Betonların Düşük Sıcaklıklardaki Davranışının Tahribatsız Yöntemlerle İncelenmesi
}

\author{
${ }^{* 1}$ Ümit YURT, ${ }^{2}$ Mehmet EMİROĞLU \\ ${ }^{1}$ Düzce Üniversitesi, Düzce MYO, İnşaat Bölümü, Düzce/TÜRKİYE, umityurt@ duzce.edu.tr, \\ ${ }^{2}$ Düzce Üniversitesi, Teknoloji Fakültesi, İnşaat Mühendisliği Bölümü, Düzce/TÜRKIYYE, \\ mehmetemiroglu@duzce.edu.tr, \\ Araştırma Makalesi \\ Geliș Tarihi: 01.03.2018 \\ Kabul Tarihi: 27.06 .2018
}

$\ddot{O} \mathbf{z}$

Yapıların hasara uğratılmadan test edilmesinde tahribatsız test yöntemlerinden olan ultrases geçiş hızı ve rezonans frekansından yararlanılarak malzeme özelliklerinin belirlenmesi sıklıkla tercih edilmektedir. Dinamik elastisite modülü değeri beton numunelerin donma çözünme dirençleri hakkında fikir vermekle birlikte özellikle dinamik yüklemeler altında tasarım yapılırken kullanılan bir karakteristiktir. Bu çalışmada betonun kriyojenik sıvı ile teması sonucunda ortaya çıkabilecek etkiler ve beton davranışı tahribatsız yöntemlerle incelenmiştir. Bu kapsamda Yüksek Fırın Cürufu (YFC) Uçucu Kül (UK) ve Silis Dumanı (SD) kullanılarak hazırlanan yüksek dayanımlı kendiliğinden yerleşen beton tasarımı gerçekleştirilmiştir. Su, örtü ve hava küründe 28,56 ve 90 gün dayanım kazanan numuneler kriyojenik sıvıya maruz bırakılmıştır. Kriyojenik sıvı etkisinde kalan numuneler üzerinde, dinamik elastisite modülü ve ultrases geçiş hızı deneyleri yapılmıştır. Sonuç olarak, dinamik elastisite modülü ve Ultrases geçiş hızı değerlerinin kriyojenik sıvıya maruz kalma süresinin artışı ile azaldığı görülmüştür. Ayrıca tüm kür süresi ve kür tipi incelendiğinde en yüksek $\mathrm{R}^{2}$ değerlerini SD numunelerinin aldığı gözlemlenmiştir.

Anahtar Kelimeler: Kriyojenik Sıcaklık, Beton Depolama Tankı, Rezonans Frekansı, Ultrases Geçiş Hızı

\section{Analyzing the Low-Temperature Behavior of Self-Compacting Concretes through Non-Destructive Testing Methods}

\author{
${ }^{* 1}$ Ümit YURT, ${ }^{2}$ Mehmet EMİROĞLU \\ ${ }^{1}$ Düzce Üniversitesi, Düzce MYO, İnşaat Bölümü, Düzce/TÜRKİYE, umityurt@ duzce.edu.tr \\ ${ }^{2}$ Düzce Üniversitesi, Teknoloji Fakültesi, İnşaat Mühendisliği Bölümü, Düzce/TÜRKİYE, \\ mehmetemiroglu@duzce.edu.tr
}

\begin{abstract}
Among the non-destructive testing methods, ultrasonic pulse velocity and resonant frequency are often used to determine material properties. The dynamic modulus of elasticity provides information about the freeze-thaw resistance of concrete specimens and is a characteristic used especially in designs under dynamic loading. This study investigated the possible effects of the contact of concrete with a cryogenic liquid and the behavior of concrete using non-destructive testing methods. To this end, a highstrength self-compacting concrete mix was designed using blast-furnace slag (BFS), fly ash (FA), and silica fume (SF). The water-cured, membrane-cured and air-cured specimens gaining strength for 28, 56, and 90 days were exposed to the cryogenic liquid. The dynamic modulus of elasticity test and ultrasonic pulse velocity test were performed on the specimens exposed to the cryogenic liquid. The test results indicated that the dynamic modulus of elasticity value and the ultrasonic pulse velocity value decreased with the increase in the time of exposure to the cryogenic liquid. Considering the curing times and curing methods, the $\mathrm{SF}$ specimens had the highest $\mathrm{R}^{2}$ values.
\end{abstract}

Keywords: Cryogenic Temperature, Concrete Tank, Resonance Frequency, Ultrasonic Pulse Velocity 


\section{GÍRİ̧̧}

Kriyojenik sıvıların büyük miktarlarda depolanması, güvenle saklanması ve ihtiyaç halinde güvenli bir şekilde talebin karşılanmasında beton muhafazalı tanklar yaygın olarak kullanılmaktadır. Bu tür tank uygulamalarında kullanılacak olan betonun mekanik performansının yüksek olması, kalıba boşluksuz yerleşmesi ve kriyojenik sıcaklıklara dayanıklı olması gerekmektedir. Tüm bu özellikler son yıllara yaygın olarak kullanılan Kendiliğinden Yerleşen Betonlardan (KYB) sağlanan özelliklerdendir [18]. Literatür incelendiğinde kriyojenik sıcaklıklardaki geleneksel beton davranışı ile ilgili çalışmalar bulunmaktadır [9-14]. Lee ve arkadaşları (1988) yapmış oldukları çalışmalarında +20 ile $-70^{\circ} \mathrm{C}$ aralığındaki farklı sıcaklıklarda betonun elastisite modülü, yarmada çekme dayanımı, basınç dayanımı ve donatı aderanslarını belirlemişlerdir. $\mathrm{Bu}$ çalışmada sıcaklıktaki düşüşe bağlı olarak tüm dayanımlarda bir artış olduğu vurgulanmıştır. Basınç dayanımındaki artışın elastisite modülü, yarmada çekme ve donatı aderansı değerlerindeki artışa göre daha yüksek olduğu bildirilmiştir [15].

Berner ve Gerwick (1985) taşıyıcı hafif betonların, kriyojenik sıcaklıklarda statik ve tekrarlı yükler altındaki davranışını araştırmışlardır. Sonuç olarak yüksek dayanımlı hafif betonların mükemmel kriyojenik özellik sergilediği ve sıvılaştırılmış gaz tanklarında ikincil bir bariyer olarak kullanılabileceğini bildirmişlerdir [10].

Vandewalle (1989) test sicaklığ $(20,-40,-80,-120$ ve -180 oC) ve kür koşullarının beton davranışına etkisini araştırmak üzere bir çalışma gerçekleştirmiştir. Sıcaklıktaki düşüşe bağlı olarak donatı aderansında bir artış gözlendiği bildirilmiştir [14]. Pusch ve Rostasy (1987) çok düşük sıcaklık çevriminin taşıyıcı hafif betonların dayanım, şekil değiştirme ve termal genleşme özelliklerine etkisini araştırmışlardır. Çalışmada, $45 \mathrm{MPa}$ dayanıma sahip taşıyıcı hafif betonlar kullanılmıştır. Sonuç olarak taşıyıcı hafif betonların mekanik özelliklerinin çimento pastası ile boşluklu agreganın nem oranına bağlı olduğu bildirilmiştir [13]. Elices ve arkadaşları (1989) -170 oC ve oda sıcaklığındaki beton numunelerinin kırılma performanslarını araştırmışlardır. Sıcaklığın azalmasıyla gerilme yoğunluk faktörü değerinde bir azalma olduğu bildirilmiştir [16]. Hanaor (1982) betonun kriyojenik koşullar altındaki mekanik özellikleri dışında farklı bir çalışma yaparak, su yerine sıvı nitrojen kullanımının betonun geçirimliliğine etkisini araştırmıştır. Elde edilen sonuçlar, kriyojenik sıcaklıklarda betonun geçirgenliğini düzenleyen mekanizmaların normal sıcaklıklarda geçerli olanlardan önemli ölçüde farklılık göstermediği yönündedir. Çalışmada, özellikle agrega ve çimento pastası ara yüzey etkileşiminin önemli bir rol oynadığı kaydedilmiştir [12]. Yurt ve arkadaşları (2015) su küründe dayanım kazanmış numuneleri bir çevrim kiriyojenik donma çözülme etkisinde bırakarak, dinamik elastisite modulü, ultrases geçiş hızı, basınç ve eğilme dayanımı deneyleri gerçekleştirmişlerdir. Sonuç olarak kendiliğinden yerleşen betonların bir çevrim kriyojenik sıvı etkisi ile dinamik elastisite modülü ve ultrases geçiş hızı değerlerinde referans numuneye göre düşüş, basınç ve eğilme dayanımı değerlerinde ise yaklaşık \% 10 oranında artış olduğu bildirilmiştir [6]. Yurt ve arkadaşları (2016) hava kürü uygulanmış numuneler üzerinde 90 günlük kür süresini takiben, bir çevrim kriyojenik sıcaklık sonrası, dinamik elastisite modulü, ultrases geçiş hızı, basınç ve eğilme dayanımı değerlerindeki değişimi aştırmışlardır. Sonuç olarak hava küründe dayanım kazanan kendiliğinden yerleşen betonların düşük sıcaklıklardaki sıvı etkisi ile ultrases geçiş hızı ve dinamik elastisite modülü, değerlerinde referans numuneye göre kayda değer bir değişim gözlenmediği, Basınç ve eğilme dayanımı değerlerinde ise düşük sıcaklıklardaki sıvı azot etkisi sonucunda, basınç dayanımında artış görülürken eğilme dayanımı değerleri tahribatsız deney sonuçları ile paralellik gösterdiği bildirilmiştir [6].

Günümüze kadar yapılan çalışmalar incelendiğinde, geleneksel betonların kriyojenik sıcaklıklar altındaki davranışı genel olarak sıcaklığın azalmasıyla mekanik özelliklerdeki artış şeklinde ifade edilmektedir. $\mathrm{Bu}$ çalışmada, tekrarlı kiryojenik işleme maruz bırakılan farklı kür koşullarında kürlenmiş KYB betonların tahribatsız test yöntemlerinden, rezonans frekansı ve ultrases geçiş hızı özelliklerindeki değişim incelenmiştir.

\section{DENEYSEL ÇALIŞMA}

\subsection{Malzemeler ve Numune Hazırlama}

Bu çalışmada KYB karışımlarının üretilmesinde, her bir kür tipi ve kür süresi için üçer adet numune üretilmiştir. Bu numunelerde toz malzeme olarak YFC, UK ve SD, CEM I 42,5 $\mathrm{R}$ tipi Portland çimentosu, agrega, su ve hiperakışkanlaştırıcı kullanılmıştır. Kimyasal bileşen oranı esas alınarak ASTM C 618 ve TS EN 197-1' e göre, karışımda kullanılan uçucu kül puzolonik aktiviteye sahip, düşük kireçli F sınıfı uçucu küldür. Çalışmada kullanılan hiper akışkanlaştırıcı beton katkısı "Sika Viscocrete HiTech 79', Sika Yapı Kimyasalları A.Ş.'den temin edilmiştir. YFC, UK, SD ve CEM I 42,5 R tipi çimentoya ait kimyasal, fiziksel ve mekanik özellikler Tablo 1'de verilmiştir.

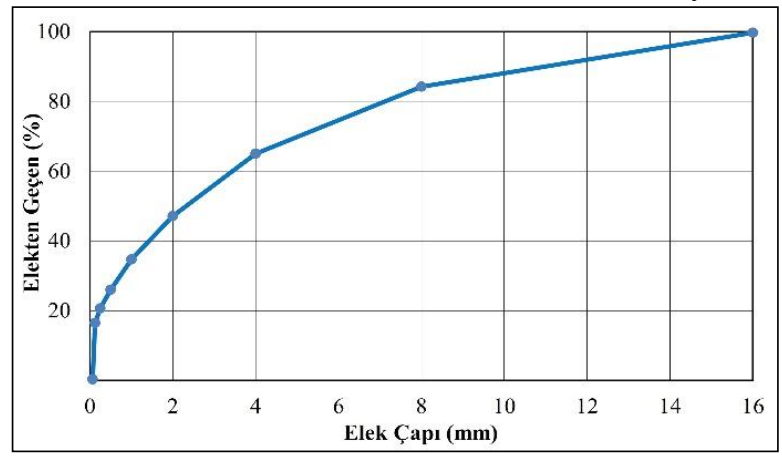

Şekil 2.1. Kullanılan agregaya ait granülometri eğrisi

Çalışmada en büyük dane çap1 $16 \mathrm{~mm}$ olan, kireçtaşı kullanılmıştır. Kullanılan agregaya ait elek analizi sonuçları Şekil 2.1' de verilmiştir. 
Tablo 1. CEM I 42,5 R tipi çimento ve toz malzemelere ait teknik özellikler

\begin{tabular}{|c|c|c|c|c|c|c|}
\hline $\begin{array}{l}\text { Kimyasal } \\
\text { Kompozisyon (\%) }\end{array}$ & $Y F C$ & $S D$ & $\boldsymbol{U} \boldsymbol{K}$ & $\begin{array}{l}C E M I \\
42,5 R\end{array}$ & Çimentonun Fiziksel özellikle & \\
\hline $\mathrm{SiO}_{2}$ & 40,54 & 96,0 & 58.56 & 18,95 & Priz başlanglcı (sa/dk) & $02: 18$ \\
\hline $\mathrm{Fe}_{2} \mathrm{O}_{3}$ & 1,12 & 0,25 & 6.51 & 4,07 & Priz sonu $($ sa/dk) & $03: 54$ \\
\hline $\mathrm{TiO}_{2}$ & 0,96 & - & 1.21 & - & Hacim sabitliği (mm Toplam) & 1,32 \\
\hline $\mathrm{Al}_{2} \mathrm{O}_{3}$ & 14,58 & 0,70 & 23.39 & 5.32 & $\ddot{O} z g \ddot{u} l$ ăgırlık & 3,16 \\
\hline $\mathrm{CaO}$ & 34,19 & 0,50 & 1.81 & 64,71 & Özgül yüzey $\left(\mathrm{cm}^{2} / \mathrm{g}\right)$ & 4209 \\
\hline $\mathrm{MgO}$ & 7,28 & 0,60 & 2.02 & 1,36 & Elek üstü $(45 \mu) \%$ & 3,64 \\
\hline $\mathrm{Na}_{2} \mathrm{O}$ & 0,58 & 0,25 & 0.53 & 0,16 & \multicolumn{2}{|l|}{ Basınç dayanımı (MPa) } \\
\hline $\mathrm{K}_{2} \mathrm{O}$ & 1,1 & 0,85 & 4.13 & 0,51 & 2. Gün & 31,11 \\
\hline $\mathrm{SO}_{3}$ & 0,16 & 0,50 & 0.0013 & 2,7 & 7. Gün & 39,61 \\
\hline Toplam Alkali & - & & & 0,61 & 28.Gün & 55,22 \\
\hline Kıdırma Kaybı & - & & & 4,21 & \multirow{2}{*}{\multicolumn{2}{|c|}{ Eğilme Dayanımı (MPa) }} \\
\hline Çözünmeyen kalıntı (\%) & - & & & 0,68 & & \\
\hline $\mathrm{SCaO}(\%)$ & - & & & 1,41 & 28. Gün & 8,45 \\
\hline
\end{tabular}

\subsection{KYB Karışım Tasarımı}

Çalışmada üç farklı toz malzeme ile üretimi yapılan KYB karışım oranları Tablo 2' de verilmiştir. Tabloda belirtilen ölçülerdeki malzemelerden ilk olarak agregalar beton mikserine aktarılmış, ince ve iri agregaların karıştırılmasının ardından ayrı bir kapta karıştırılan çimento ve toz malzeme agregalarla birlikte kuru olarak tekrar karıştırılmıştır.

Homojen bir dağılıma ulaşılmasının ardından, su eklenmiş iki dakika boyunca karıştırılmasının ardından, hiper akışkanlaştırıcı katkı eklenerek bir dakika boyunca karıştırılarak KYB elde edilmiştir.

\section{KYB Oranları}

Üretilen kendiliğinden yerleşen beton karışımları EFNARC'de [2] belirtilmiş olan ve duvar elemanlarında kullanılması önerilen SF2 (660-750 mm hedef slump yayılma çapı) KYB özellikleri akışkanlık sınıfı hedef alınarak belirlenmiştir. Deneylerde üç farklı toz malzeme kullanılarak hazırlanan karışım oranları Tablo 2'de verilmiştir. Verilen bu oranlara göre hazırlanan taze beton numuneleri üzerinde EFNARC 2005'e uygun olarak, kendiliğinden yerleşen beton deneyleri gerçekleştirilmiştir. Gerçekleştirilen bu deneyler sonucunda elde edilen değerler Tablo 2' de özetlenmiştir. Basınç dayanım değerleri üç farklı KYB karışımını temsil etmekte olup, su küründe 28 gün dayanım kazanan standart küp numunelere ait değerlerdir.

Tablo 2. KYB karışım miktarları $\left(1 \mathrm{~m}^{3}\right)$

\begin{tabular}{c|c|c|c|}
\multicolumn{2}{c}{$\begin{array}{c}\text { Bileşenler } \\
\text { ve } \\
\text { Temel Ö̈ellikler }\end{array}$} & \multicolumn{3}{|c|}{ Karışım Oranlart } \\
\cline { 2 - 4 } Cem I $\left(\mathrm{kg} / \mathrm{m}^{3}\right)$ & KYB-YFC & KYB-UK & KYB-SD \\
\hline Puzolan $\left(\mathrm{kg} / \mathrm{m}^{3}\right)$ & 175 & 375 & 495 \\
\hline T. Filler $\left(\mathrm{kg} / \mathrm{m}^{3}\right)$ & 550 & 175 & 55 \\
\hline Su $\left(\mathrm{kg} / \mathrm{m}^{3}\right)$ & 193 & 550 & 215 \\
\hline Su/Çimento & 0,35 & 193 & 0,39 \\
\hline K. Maddesi $\left(\mathrm{kg} / \mathrm{m}^{3}\right)$ & 7,98 & 0,35 & 9,63 \\
\hline
\end{tabular}




\begin{tabular}{c|c|c|c}
\hline Ince Agrega $\left(\mathrm{kg} / \mathrm{m}^{3}\right)$ & 1077 & 1085 & 1045 \\
\hline Iri Agrega $\left(\mathrm{kg} / \mathrm{m}^{3}\right)$ & 580 & 584 & 563 \\
\hline Slamp-Akış $(\mathrm{mm})$ & 737,5 & 707,5 & 752,5 \\
\hline Slamp-Akış $T_{500}(\mathrm{~s})$ & 6,00 & 17,00 & 10,50 \\
\hline L-Box $\left(\mathrm{h}_{1} / \mathrm{h}_{2}\right.$ oranı) & 0,84 & 0,81 & 0,81 \\
\hline $\begin{array}{c}\text { Taze Beton Birim Ağırlık } \\
\left(\mathrm{kg} / \mathrm{m}^{3}\right)\end{array}$ & 2372,2 & 2352,3 & 2313,5 \\
\hline Basınç Dayanımı $(\mathrm{MPa})$ & 87,11 & 77,76 & 73,87 \\
\hline
\end{tabular}

\subsection{Numunelerin Kriyojenik Sıcaklığa Maruz Bırakılması}

Üretilen numuneler Şekil 2.2 de görülen özel tank içerisinde 28,56 ve 90 günlük kür süreleri ardından kriyojenik etkiye (sıvı azot ile temas $-196^{\circ} \mathrm{C}$ ) maruz bırakılmıştır. Oluşturulan kiriyojenik etki bir saat özel tank içersinde kriyojenik sıvı (sıvı azot $-196{ }^{\circ} \mathrm{C}$ ) ile temas ardından, labaratuvar ortamında 24 saat $+20{ }^{\circ} \mathrm{C}$ oda sıcaklığında çözülme olarak gerçekleştirilmiştir. Numuneler kriyojenik sıvıya maruz bırakılmadan hemen önce tahribatsı testler gerçekleştirilmiştir. $\mathrm{Bu}$ işlemler bir gün arayla beş gün tekrarlanmıştır.

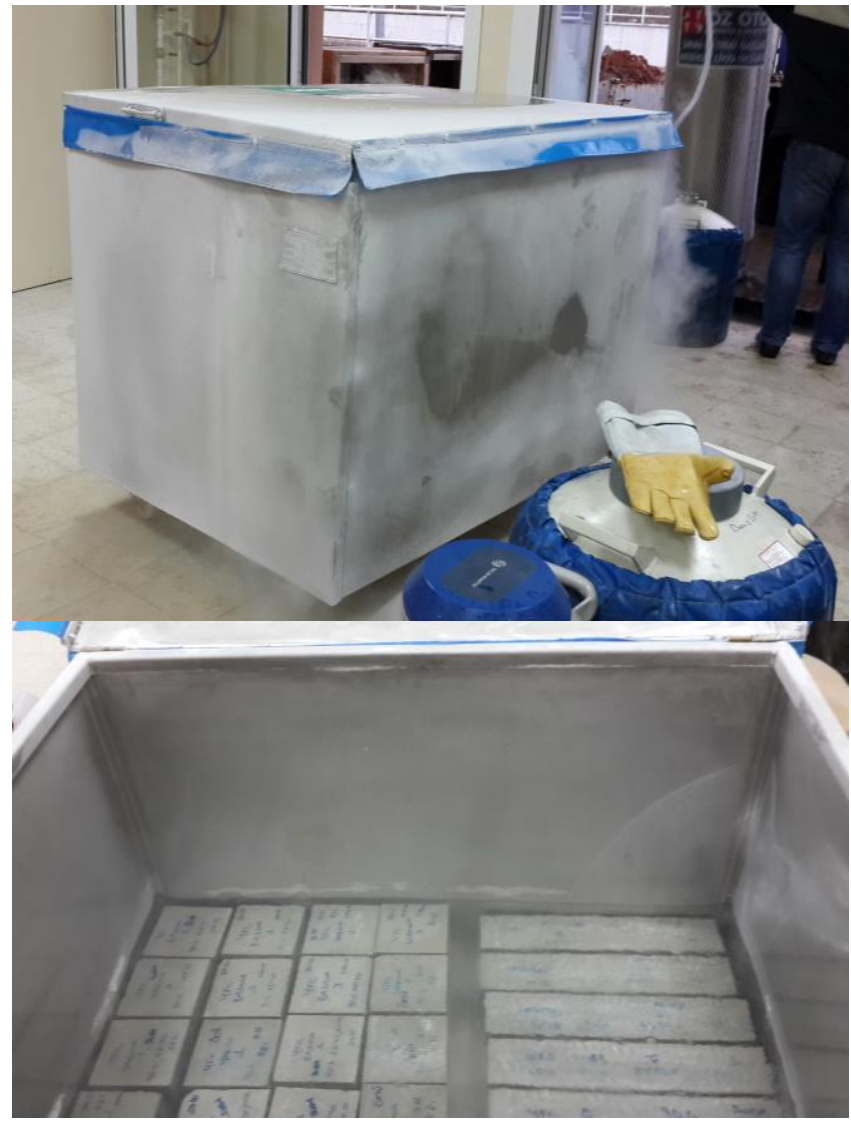

Şekil 2.2. Kriyojenik etki, numunelerin görünümü

\subsection{Tahribatsız testler}

Farklı toz malzeme kullanılarak elde edilen numuneler 28,56 ve 90 gün su, örtü ve hava küründe dayanım kazandıktan sonra, Şekil 2.2'de görüldüğü gibi kriyojenik tank içerisinde sıvı azot aracılığı ile düşük sıcaklıklara maruz bırakılmıştır. Çalışmada dinamik elastisite modülü değerleri, rezonans frekansı deneyi (ASTM 215) sonucunda hesaplanmıştır. Rezonans frekansı ve ultrases geçiş hızı deneyleri 100x100x500 mm boyutunda prizmatik kiriş numuneler üzerinde gerçekleştirilmiştir. Ultrases geçiş hızı ve rezonans frekansı deneylerinin gerçekleştirildiği prizmatik kiriş numuneler Şekil 2.2'de kriyojenik tank içerisinde sağ tarafta görülmektedir.

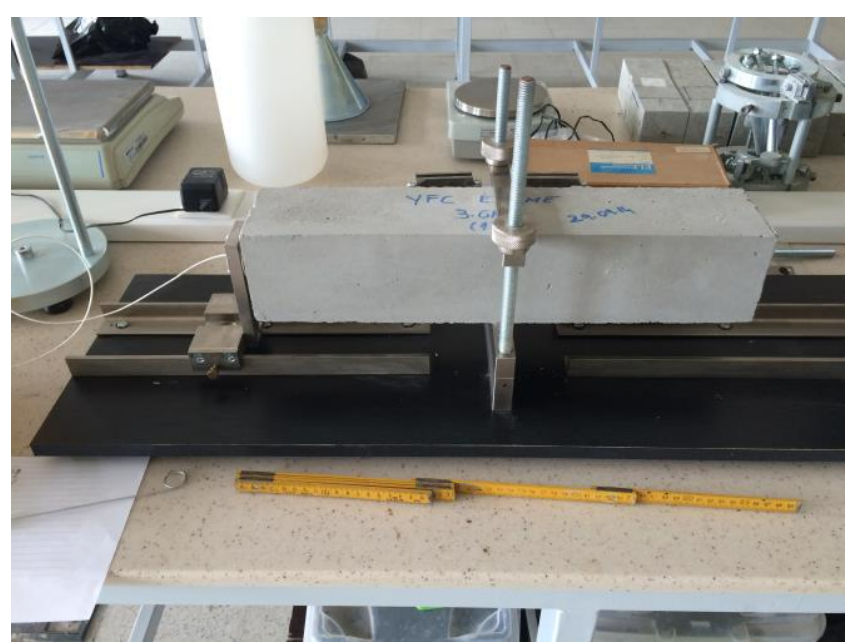

Şekil 2.3. Boyuna rezonans frekansı ölçümü

Her bir çevrim ardından ölçülen rezonans frekansı değerlerinden faydalanılarak Denklem 2.1 yardımıyla dinamik elastiste modülü değerleri hesaplanmıştır.

$$
E_{d}=4 L^{2} \rho N^{2} \times 10^{-12}(\mathrm{MPa})
$$

Burada $\mathrm{E}_{\mathrm{d}}$, dinamik elastiste modülü, $\mathrm{L}$, numune uzunluğu (mm), $\rho$, malzeme yoğunluğu $\left(\mathrm{kg} / \mathrm{m}^{3}\right), \mathrm{N}$, boyuna rezonans frekansidir $(\mathrm{Hz})$. 
Üretilen sertleşmiş beton kiriş numuneleri 28, 56 ve 90 gün su, örtü ve hava küründe dayanım kazandıktan sonra, her bir kriyojenik sıvı etkisi ardından, ultrases geçiş hızı ölçümleri gerçekleştirilmiş. Denklem 2.2 yardımıyla ultrases geçiş hızı değerleri hesaplanmıştır. Burada V, Ultrases geçiş hızı,

$$
V=\frac{S}{t}\left(\frac{k m}{s n}\right)
$$

$\mathrm{S}$, numune uzunluğu $(\mathrm{km})$, t, Ultrases geçiş süresi (sn) olarak verilmiştir.

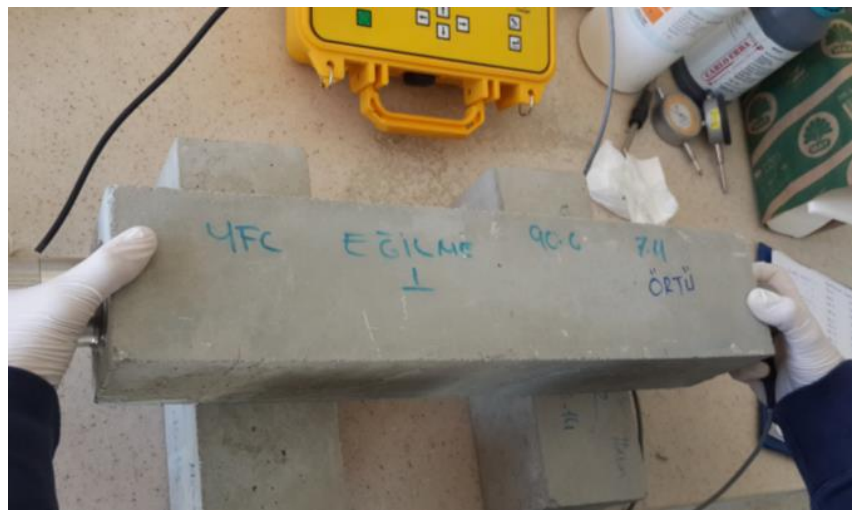

Şekil 2.4. Ultrases geçiş hızı ölçümü

Ayıca dinamik elastisite değerleri, ultrases geçiş hızı değerleri kullanılarak Denklem 2.3 yardımıyla tekrar hesaplanmıştır.

$$
E_{d}=V^{2} \rho \frac{(1+\mu)(1-2 \mu)}{(1-\mu)}
$$

Burada $\mathrm{E}_{\mathrm{d}}$, dinamik elastiste modülü (Mpa), V, ultrases geçiş hızı $(\mathrm{km} / \mathrm{s}), \rho$, malzeme yoğunluğu $\left(\mathrm{kg} / \mathrm{m}^{3}\right), \mu$, poisson oranı, olarak verilmiştir.

\section{BULGULAR VE TARTIŞMA}

Her bir kriyojenik etki ardından (100x100x500 mm) prizmatik kirişler üzerinde yapılan boyuna rezonans frekansı ölçümleri sonucunda elde edilen değerler kullanılarak hesaplanan dinamik elastisite modülü değerleri Şekil 3.1'de sütun grafik olarak verilmiştir. Grafikte kriyojenik etki sayısına bağlı olarak farklı kür koşullarında dayanım kazanan farklı toz malzeme içeriğine sahip numunelerin dinamik elastisite modülündeki değişim görülmektedir.

Genel olarak dinamik elastisite modülünün kriyojenik sıvıya maruz kalma süresinin artışı ile azaldığı görülmektedir. Kür süreleri ve dinamik elastisite değerleri arasındaki ilişki incelendiğinde en fazla değişimin su küründe dayanım kazanan numunelerde olduğu, ayrıca 28 gün su küründe dayanım kazanan numunelerdeki değişimin 56 ve 90 güne göre daha fazla olduğu görülmüştür. Bu duruma betonun dayanım kazanmaya devam etmekte olduğu ve betonun nem içeriğinin kriyojenik sıv1 etkisi ile betonun hasara uğramasında önemli rol oynadığı düşünülmektedir.
Hava küründe dayanım kazanan numunelerin 28,56 ve 90 günlük kür süreleri ile birlikte değerlendirildiğinde dinamik elastiste değerlerindeki değişimin daha az olduğu görülmektedir. Genel olarak kriyojenik sıv1 etkisi ile dinamik elastiste modülündeki değişimin YFC içeren betonlarda daha yüksek ve birbirine yakın değerler aldığ görülmüştür.

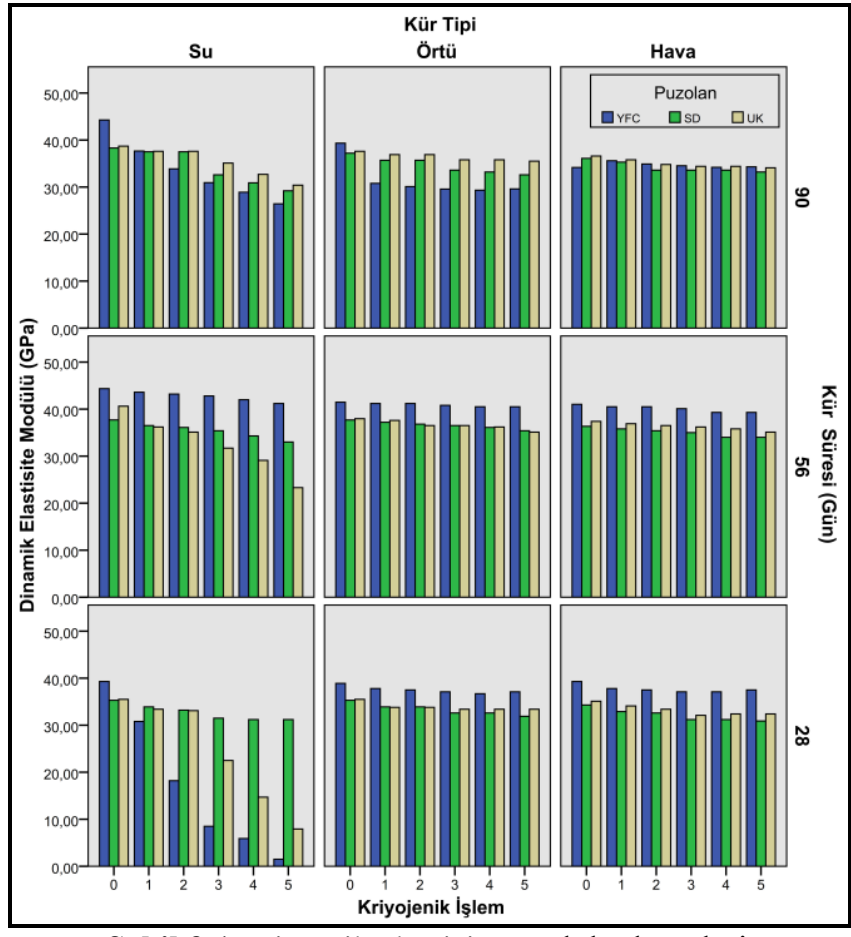

Şekil 3.1. Dinamik elastisite modülü değerleri

Şekil 3.1 ve Şekil 3.2 karşılaştırmalı olarak incelendiğinde dinamik elastisite modülü değerleri ile ultrases geçiş hızı değerlerinin birbiri ile uyumlu olduğu söylenebilir. Tüm kür günleri ve kür metoduna bağlı olarak silis dumanı içeren numunelerin dinamik elastisite modülü değerlerindeki değişim sınırlı kalmıştır.

Dinamik elastisite modülü değerlerinde en büyük azalmaların su kürü uygulanmış numunelerden elde edildiği Şekil 3.1.’den görülmektedir.

Su kürü numuneleri göz önüne alındığında 28 gün su kürü uygulanan $\mathrm{YFC}, \mathrm{SD}$ ve $\mathrm{UK}$ numunelerin 5 çevrim sonucunda dinamik elastisite modülü değerleri sırasıyla \%96.18, \%11.62 ve \%77.69 oranında azalma göstermiştir. 28 gün su kürü uygulanmış YFC numunelerinde 3. çevrim ardından dinamik elastisite modülü değerinde $\% 53,69$ oranında bir azalma meydana gelmiştir. 28 gün su kürü uygulanmış UK numunelerinde ise 3 . çevrim ardından dinamik elastisite modülü değerinde \%36,62 oranında bir azalma meydana gelmiştir.

Şekil 3.2 incelendiğinde genel olarak su, örtü ve hava kürü uygulanmış YFC, SD ve UK Numunelerinin ultrases geçiş hızı değerleri her çevrimin ardından azalma eğilimindedir. Su kürü uygulanmış numunelerde, hava ve örtü altında kür 
uygulanmış numunelere kıyasla daha düşük ultrases geçiş hızı değerlerine ulaşılmıştır.

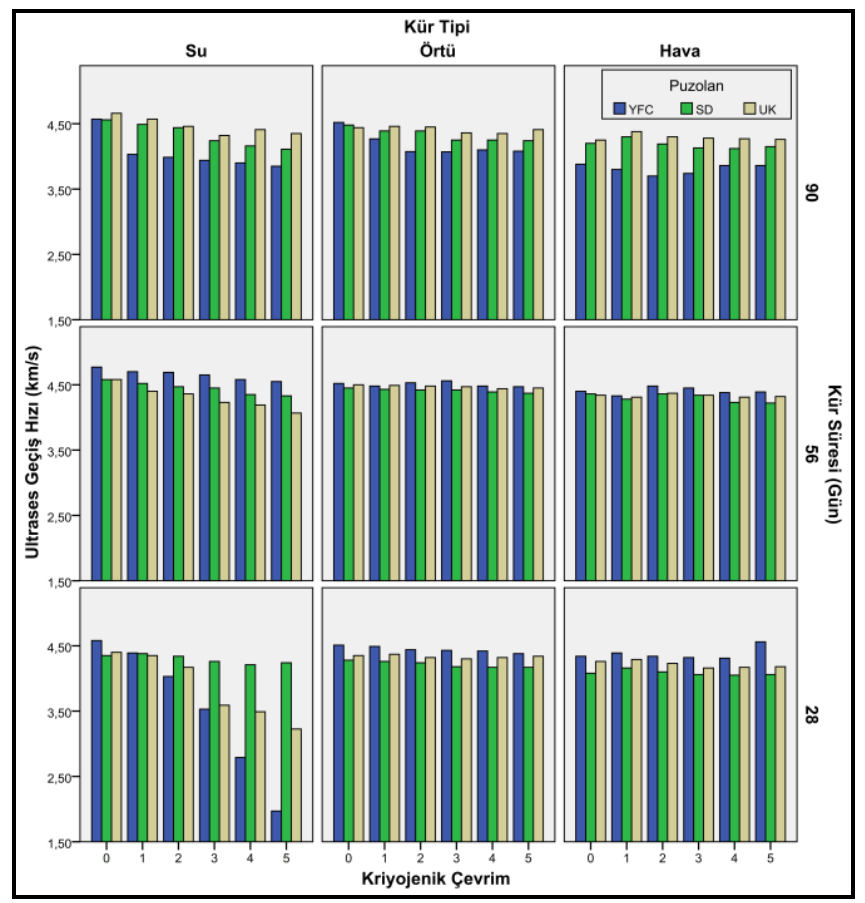

Şekil 3.2. Ultrases geçiş hızı değerleri

Özellikle 28 günlük su kürü uygulanmış YFC ve UK numunelerinin tekrarlı kriyojenik sıvı etkisi ardından ultrases geçiş hızı değerleri doğrusal bir azalma göstermiştir. 28 günlük kür uygulaması ardından 5 çevrim kriyojenik sıvıya maruz kalmış YFC numunelerinin ultrases geçiş hızı değerlerinde \%56,99 UK numunelerinde ise \%26,59 oranında azalma meydana gelmiştir. Şekil 3.2 incelendiğinde genel olarak su, örtü ve hava kürü uygulanmış YFC, SD ve UK Numunelerinin ultrases geçiş hızı değerleri her çevrimin ardından azalma eğilimindedir.

Su kürü uygulanmış numunelerde, hava ve örtü altında kür uygulanmış numunelere kıyasla daha düşük ultrases geçiş hızı değerlerine ulaşılmıştır. Özellikle 28 günlük su kürü uygulanmış YFC ve UK numunelerinin tekrarlı kriyojenik sıvı etkisi ardından ultrases geçiş hızı değerleri doğrusal bir azalma göstermiştir. 28 günlük kür uygulaması ardından 5 çevrim kriyojenik sıvıya maruz kalmış YFC numunelerinin ultrases geçiş hızı değerlerinde \%56,99 UK numunelerinde ise $\% 26,59$ oranında azalma meydana gelmiştir.

Ultrases geçiş hızı değerlerinden faydalanılarak denklem 2.3 yardımıyla dinamik elastiste modülü değerleri hesaplanmıştır. Hesaplanan bu değerler kullanılarak oluşturulan grafik Şekil 3.3' de görülmektedir. Şekil 3.3 incelendiğinde ultrases geçiş hızı değerlerinden elde edilen dinamik elastiste modülü değerleri ile Şekil 3.1'de rezonans frekansı kullanılarak elde edilen değerler incelendiğinde genel olarak her iki grafiğin birbiri ile uyumlu olduğu görülmektedir. Ayrıca denklem 2.1 ve denklem 2.3 ile hesaplan değerler lineer regresyon analizi ile değerlendirilmiştir (Şekil 3.4).

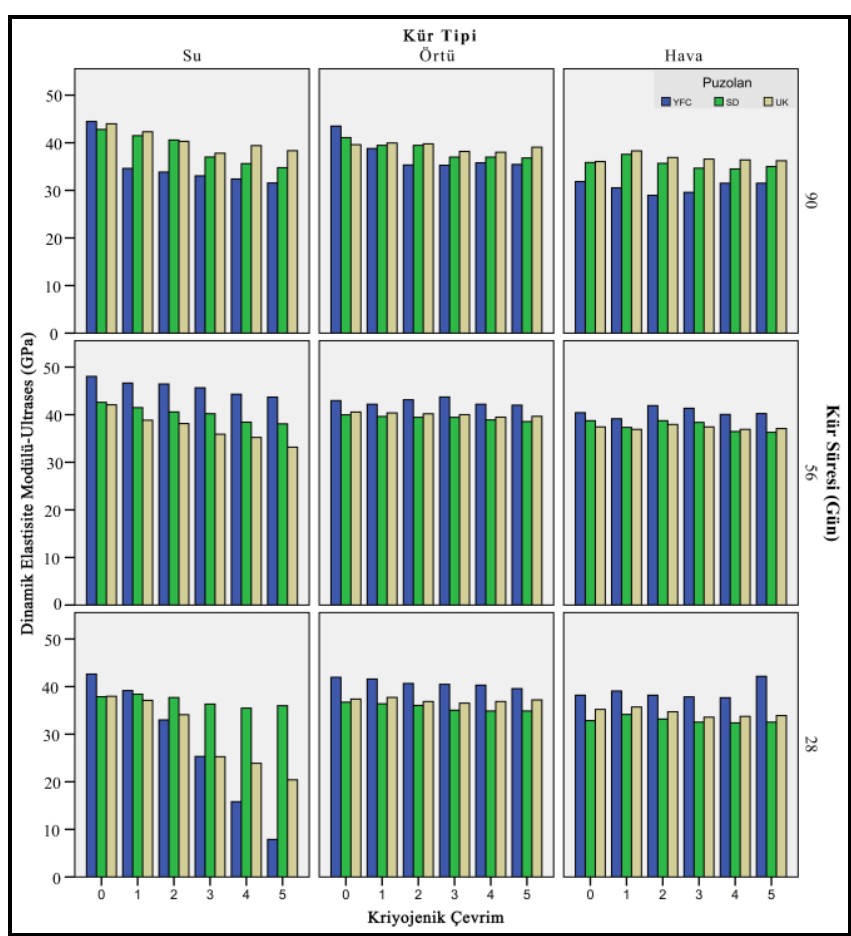

Şekil 3.3. Ultrases geçiş hızı değerlerinden elde edilen dinamik elastisite modülü değerleri

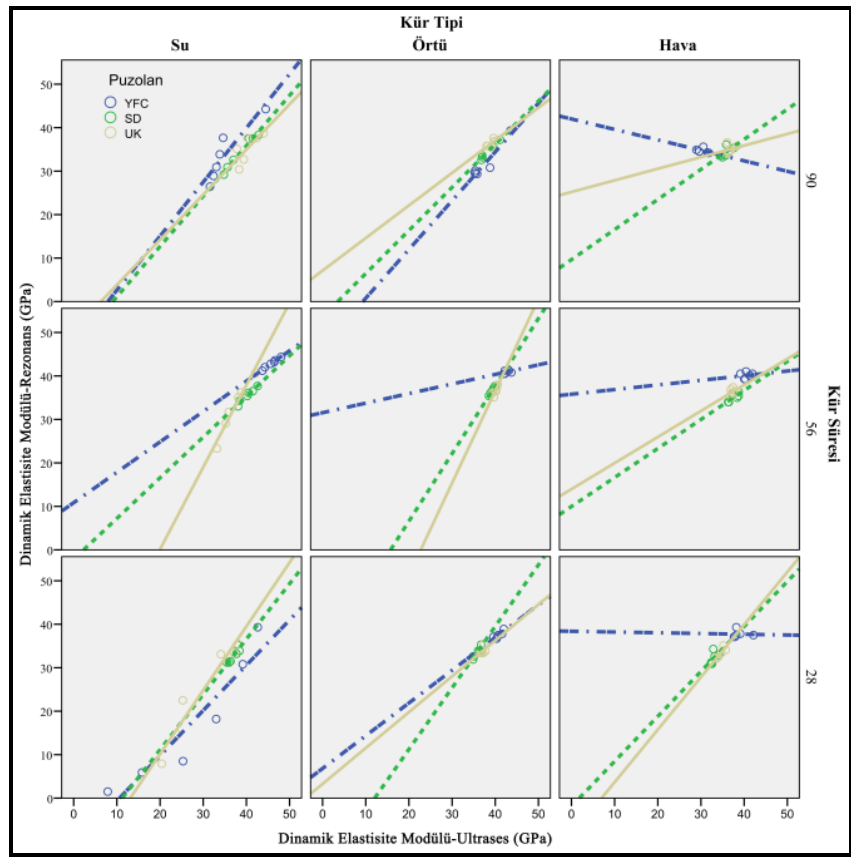

Şekil 3.4. Rezonans ve ultrases değerlerinden elde edilen dinamik elastisite modülü değerlerinin regresyon analizi

Şekil 3.4 incelendiğinde, kür tipi ve kür süresinden bağımsız olarak SD ve UK içeren numunelerin dinamik elastisite modülleri arasında lineer bir ilişkinin bulunduğu açıkça görülmektedir. Bunun yanında, 28, 56 ve 90 gün hava küründe ve 56 gün örtü küründe dayanım kazanan serilerin dışında YFC içeren numunelerin de dinamik elastisite modülleri arasında benzer bir ilişki tespit edilmiştir. YFC 
kullanılan 28 ve 56. Günlerde Hava kürü yapılmış numunelerin ve 56 günlük Örtü ile kürlenmiş numunelerin lineer regresyon analizi sonucunda determinasyon katsayıs $\left(\mathrm{R}^{2}\right)$ değerleri düşük çıkmıştır. Bu durumun YFC'nin UK ve SD'ına göre donma çözünme etkisine daha dirençli olmasından kaynaklandığı düşünülmektedir. Şekil 3.2 ve Şekil 3.3 incelendiğinde bahsi geçen YFC katkılı serilerin ultrases geçiş hızı ve rezonans frekansı değerlerinin kriyojenik etkiden düşük düzeyde etkilendiği görülmektedir. Rezonans frekansı ve ultrases geçiş hızı sonuçlarından elde edilen dinamik elastisite modülü değerleri lineer regresyon analizi ile karşılaştırmalı olarak analiz edilmiştir. Bu analiz neticesinde elde edilen determinasyon katsayıları Tablo 3 'de görülmektedir.

Tablo 3. Determinasyon katsayıları $\left(\mathrm{R}^{2}\right)$

\begin{tabular}{|c|c|c|c|c|}
\hline \multicolumn{5}{|c|}{ Regresyon Analizi $\left(R^{2}\right)$ Değerleri } \\
\hline \multirow{2}{*}{$\begin{array}{c}\text { Kür } \\
\text { Süresi } \\
\text { (Gün) }\end{array}$} & \multirow{2}{*}{ Kür Tipi } & \multicolumn{3}{|c|}{ Karışım } \\
\hline & & $Y F C$ & $S D$ & $\boldsymbol{U} \boldsymbol{K}$ \\
\hline \multirow{3}{*}{28} & $S U$ & 0,886 & 0,79 & 0,938 \\
\hline & $\ddot{O} R T \ddot{U}$ & 0,72 & 0,911 & 0,188 \\
\hline & $\boldsymbol{H A V A}$ & 0,001 & 0,268 & 0,8 \\
\hline \multirow{3}{*}{56} & $S U$ & 0,982 & 0,958 & 0,958 \\
\hline & $\ddot{O} R T \ddot{U}$ & 0,134 & 0,962 & 0,728 \\
\hline & $\boldsymbol{H A} \boldsymbol{V A}$ & 0,022 & 0,613 & 0,087 \\
\hline \multirow{3}{*}{90} & $S U$ & 0,833 & 0,974 & 0,581 \\
\hline & $\ddot{O} R T \ddot{U}$ & 0,902 & 0,978 & 0,562 \\
\hline & $H A V A$ & 0,263 & 0,445 & 0,05 \\
\hline
\end{tabular}

Tablo 3 incelendiğinde genel olarak su küründe dayanım kazanmış (90 gün su küründe dayanım kazanan UK numunesi hariç) $\mathrm{R}^{2}$ değerlerinin $(0,79-0,974)$ yüksek sonuç verdiği gözlemlenmiştir. Tüm kür süresi ve kür tipi incelendiğinde en iyi $\mathrm{R}^{2}$ değerlerini SD numunelerinin aldığ gözlemlenmiştir. En yüksek determinasyon katsayısı değerleri 28,56 ve 90 gün su küründe dayanım kazanan YFC, SD, UK, (90 günlük UK hariç), 28 gün örtü küründe dayanım kazanan SD ve sirasiyla 56 gün örtü ve hava küründe dayanım kazanan SD, UK ve 90 gün örtü küründe dayanım kazanan YFC, SD, UK serilerden elde edilirken, en düşük determinasyon katsayıları ise 28,56 ve 90 gün hava küründe dayanım kazanan YFC, SD, UK, serileri ve sirasıyla 28 ve 56 gün örtü altında dayanım kazanan UK ve YFC serilerden elde edilmiştir.

\section{DEĞERLENDİRME VE SONUÇ}

Gerçekleştirilen bu çalışma ile farklı kür koşulları altında 28,56,90 gün dayanım kazanan farklı toz içeriğine sahip, (YFC, SD, UK) yüksek performanslı betonların aşırı düşük sıcaklıklar etkisinde elde edilen sonuçlar tahribatsız test yöntemleriyle incelenmiştir. $\mathrm{Bu}$ incelemede rezonans frekansı, ultrases geçiş hızı ve her iki tahribatsız deneyden elde edilen verilerin lineer regresyon analizi gerçekleştirilmiştir. Yapılan bu çalışmalar sonucunda ortaya çıkan veriler incelenmiş ve çıkarılabilecek bazı sonuçlar aşağıda verilmiştir.

Kür süreleri ve dinamik elastisite değerleri arasındaki ilişki incelendiğinde en fazla değişimin su küründe dayanım kazanan numunelerde olduğu, ayrıca 28 gün su küründe dayanım kazanan numunelerdeki değişimin 56 ve 90 güne göre daha fazla olduğu görülmüştür.

Hava küründe dayanım kazanan numunelerin 28,56 ve 90 günlük kür süreleri ile birlikte değerlendirildiğinde ise dinamik elastiste değerlerindeki değişimin daha az olduğu görülmektedir.

Kendiliğinden yerleşen beton tasarımında kullanılan YFC'nin UK ve SD'1na göre donma çözünme etkisine daha dirençli olmasından dolayı kriyojenik çevrimler sonucunda elde edilen değerlerin birbirine yakın sonuçlar aldığı görülmüştür.

Özellikle erken yaşlardaki dayanım kazanma sürecinde kür tipine bağlı olarak nem içeriğinin önemli rol oynadığı ve kiriyojenik çevrimler sonucunda beton içerisinde bulunan çatlakları tetikleyerek hasar mekanizmasının ilerlemesine neden olduğu sonucuna varılmıştır.

Kriyojenik sıcaklık koşulları altında nem içeriğinin önemli bir değişken olduğu, kriyojenik sıcaklık etkisi altında kalan nem içeriği yüksek betonların dinamik elastisite değerlerinin kriyojenik etki sayısının artışı ile birlikte azaldığ1 görülmüştür.

Ultrases geçiş hızı değerlerinin kriyojenik etki sayısının artışına paralel olarak azaldığı sonucuna varılmıştır.

Genel olarak kriyojenik sıv1 etkisi altında kalan betonlarda kriyojenik etki tekrarı ile dinamik elastisite ve ultrases geçiş hızı değerlerinde azalış meydana gelmiştir.

Rezonans frekansı ve Ultrases geçiş hızı deney verilerinden yararlanılarak hesaplanan dinamik elastisite modülü değerleri lineer regresyon analizi ile incelenmiştir. Tüm kür süresi ve kür tipi birlikte değerlendirildiğinde en iyi $\mathrm{R}^{2}$ değerlerini SD numunelerinin aldığ 1 gözlemlenmiştir.

Bu inceleme sonucunda, 28,56 ve 90 gün su küründe dayanım kazanan YFC, SD, UK, (90 günlük UK hariç), 28 gün örtü küründe dayanım kazanan $\mathrm{SD}$ ve sırasıyla 56 gün örtü ve hava küründe dayanım kazanan SD, UK ve 90 gün örtü küründe dayanım kazanan $\mathrm{YFC}, \mathrm{SD}$, UK serilerinden yüksek determinasyon katsayısı $\left(\mathrm{R}^{2}\right)$ değerleri elde edildiği gözlemlenmiştir.

\section{TEŞEKKÜR}

$\mathrm{Bu}$ çalışmaya maddi destek sağlayan (Proje No: BAP2015.07.05.293) Düzce Üniversitesi Bilimsel Araştırma Koordinatörlüğüne, TÜBİTAK "2211-C Öncelikli Alanlara Yönelik Doktora Bursu', ile maddi destek sağlayan, ayrıca 113M454 numaralı TÜBİTAK projesinin imkân ve olanaklarından faydalanma olanağı bulduğumuz için TÜBİTAK'a katkılarından dolayı sonsuz teşekkürlerimizi sunarız. 


\section{REFERANSLAR}

[1] P. L. Domone, "A review of the hardened mechanical properties of self-compacting concrete," Cement and Concrete Composites, vol. 29, pp. 1-12, 1// 2007.

[2] Efnarch, "The european guidelines for selfcompacting concrete: specification, production and use," ed: The european federation of specialist construction chemicals and concrete systems., 2005.

[3] P. Kumar, "Self-compacting concrete: methods of testing and design," Journal of the Institution of Engineers, vol. 86, pp. 145-150, 2006.

[4] M. H. Özkul, "Beton teknolojisinde bir devrim: kendiliğinden yerleşen-sıkışan beton," Hazır Beton Dergisi, vol. 52, pp. 64-71, 2002.

[5] M. Safiuddin, "Development of self-consolidating high performance concrete incorporating rice husk ash," University of Waterloo, 2008.

[6] Ü. Yurt, M. Emiroğlu, B. Çomak, and M. Yüksek, "The Effect of Cryogenic Temperature Conditions on the Mechanical and Physical Properties of Self-Compacting Concretes " El-Cezeri Journal of Science and Engineering, vol. 3, 2016.

[7] Ü. Yurt and M. Emiroğlu, "Doğalgaz Depolama Tankları İçin Üretilmiş Betonların Mekanik Özelliklerinin Belirlenmesi," in 1. International Conference on Engineering Technology and Applied Sciences Afyon Kocatepe University, Turkey 21-22 April 2016, (ICETAS), 2016, pp. 432-435.

[8] Ü. Yurt, "Fracture Mechanics Performance Of SelfConsolidating Concrete Exposed To Cryogenic Temperatures " Ph.D., Departmant of Composite Materials
Technologies, University of Düzce, 2015.

[9] D. E. Berner, "Behavior of prestressed concrete subjected to low temperatures and cyclic loading (cryogenic, offshore)," 8512756 Ph.D., University of California, Berkeley, Ann Arbor, 1984.

[10] D. E. Berner and B. C. Gerwick, Jr., "Static and cyclic behavior of structural lightweight concrete at cryogenic temperatures," in Ocean Space Utilization '85, W. Kato, B. C. Gerwick, Jr., M. Homma, R. Lenschow, O. T. Magoon, C. C. Mei, et al., Eds., ed: Springer Japan, 1985, pp. 439-445. [11] P. Domone and J. Illston, Construction Materials: Their Nature and Behaviour. Taylor and Francis Group eLibrary: Spon Press, 2002.

[12] A. Hanaur, "Testing of concrete specimens for permeability at cryogenic temperatures," Magazine of Concrete Research, pp. 155-162, 1982.

[13] F. S. Rostásy and U. Pusch, "Strength and deformation of lightweight concrete of variable moisture content at very low temperatures," International Journal of Cement Composites and Lightweight Concrete, vol. 9, pp. 317, 2// 1987.

[14] L. Vandewalle, "Bond between a reinforcement bar and concrete at normal and cryogenic temperatures," vol. Journal of Materials Science letters, pp. 147-149, 1989.

[15] G. Lee, T. Shih, and K. Chang, "Mechanical properties of concrete at low temperature," Journal of cold regions engineering, vol. 2, pp. 13-24, 1988.

[16] Elices M., Planas J., and Maturana P., "Fracture of Concrete at Cryogenic Temperatures," in Fracture of Concrete and Rock, S. Shah and S. Swartz, Eds., ed: Springer New York, 1989, pp. 106-116. 